\title{
Organotin Contamination in Sediments and Aquatic Organisms from the Yangtze Estuary and Adjacent Marine Environments
}

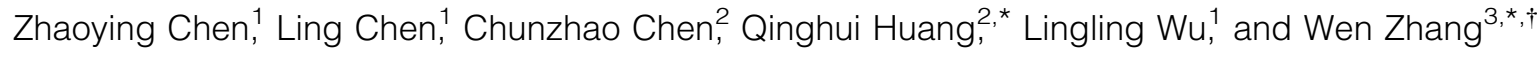 \\ ${ }^{1}$ State Key Laboratory of Pollution Control and Resources Reuse, College of Environmental Science \\ and Engineering, Tongii University, Shanghai, China. \\ ${ }^{2}$ Key Laboratory of Yangtze River Water Environment of the Ministry of Education, \\ College of Environmental Science and Engineering, Tongji University, Shanghai, China. \\ ${ }^{3}$ John A. Reif, Jr. Department of Civil and Environmental Engineering, \\ New Jersey Institute of Technology, Newark, New Jersey.
}

Received: July 18, 2016 Accepted in revised form: September 6, 2016

\begin{abstract}
Organotin compounds are man-made metallic tin complexes with hydrocarbon substituents with broad applications in food packages, pesticides, wood preservatives, antifouling, and anticorrosion paints. Marine environments near harbors often act as sinks receiving various pollutants from urban runoff, industrial discharge, and atmospheric deposition. This study presented a pioneer analysis of butyltins (BTs) and phenyltins (PhTs) in the Yangtze estuary near one of the largest harbor regions in China. The studied estuary has extensive commercial cargo activities and underdetermined distribution and levels of organotin in sediments and different biota species. Evaluating these factors is essential for determining the risk of exposure and development of future mitigation and possible preventive measures. Seventy-two surface sediments and 13 fish and crab species samples were collected from the Yangtze estuary and its adjacent East China Sea in 2014. BTs and PhTs extracted from samples with ultrasonication treatment were derivatized using sodium tetraethylborate and determined by gas chromatography coupled with mass spectrometer detector. Maximum concentrations of monobutyltin (MBT), dibutyltin (DBT), tributyltin (TBT), diphenyltin, and triphenyltin in sediments were 18.1, 8.9, 6.5, 3.9, and 3.7 ng $\mathrm{Sn} / \mathrm{g} \mathrm{dw}$ (dry weight), respectively. Higher organotin concentrations (e.g., 10-26.4 ng Sn/g dw) were found in the sediments close to the wharfs and fishing ports in the Yangtze estuary, Luchao fishing port, and Yangshan harbor. Organotin concentrations were observed to decrease with increasing distance away from coastlines, highlighting the important roles of human activities in organotin compound(OTC) presence and distribution. The butyltin degradation index indicated a rapid degradation rate of TBT and the existence of input sources for MBT and DBT in the study area. Detection rates and concentrations of organotins in biological samples (i.e., Collichthys lucidus and Carassius auratus) from Luchao port were high, which indicated escalated risks for the environment, ecosystems, and human health.
\end{abstract}

Keywords: ecological risk; marine product; organotins; sediment; yangtze estuary

\section{Introduction}

$\mathbf{O}$ RGANOTIN COMPOUNDS (OTCS) represent a group of emerging endocrine disruption substances (Hoch, 2001; Zhu et al., 2012). Its molecular formula is written as $\mathrm{R}_{\mathrm{x}} \operatorname{SnL}_{(4-\mathrm{x})}$,

*Corresponding authors: Qinghui Huang, Key Laboratory of Yangtze River Water Environment of the Ministry of Education, College of Environmental Science and Engineering, Tongji University, 1239 Siping Road, Shanghai 200092, China. Phone: +8621-65983319; Fax: +86-21-6598 6313; E-mail: qhhuang@tongii .edu.cn or Wen Zhang, John A. Reif, Jr. Department of Civil and Environmental Engineering, New Jersey Institute of Technology, 323 Martin Luther King Boulevard, Newark, NJ 07102. Phone: 1973-596-5520; Fax: +1-973-596-5790; E-mail: wzhang81@ @jit.edu ${ }^{\dagger}$ Member of AEESP. where $\mathrm{R}$ denotes an organic alkyl or aryl group and L denotes organic or inorganic ligands. Among organotin species, tributyltin (TBT), triphenyltin (TPhT), and their derivatives have been of particular concern because they were extensively used as antifouling paints on ship hulls. Furthermore, organotins have also been widely used as fungicide, polyvinyl chloride stabilizers, and wood preservatives. As a result, there is a high potential for OTCs to enter and accumulate in the aquatic environment near harbor and estuarine areas, where various pollutants are released from cargo activities and garbage discharge.

OTCs could harm different species of marine organisms (including birds and mammals) and result in negative environmental consequences (Alzieu, 1998). For instance, TBT or TPhT caused disruption of mitochondrial function,

(C) Zhaoying Chen, et al., 2019; Published by Mary Ann Liebert, Inc. This Open Access article is distributed under the terms of the Creative Commons License (http://creativecommons.org/licenses/by/4.0), which permits unrestricted use, distribution, and reproduction in any medium, provided the original work is properly cited. 
deformations in oysters, and sex changes in whelks (AntizarLadislao, 2008). The consumption of contaminated water, beverages, and marine food has been regarded as a major factor in human exposure to organotins (Ling and Sun, 2004). TBT and TPhT have been shown to cause endocrine disruption and negative impacts on the liver, immune system, and nervous system (Horiguchi et al., 1994; Whalen and Loganathan, 1999, 2001; Heidrich et al., 2001; Deng et al., 2015). Based on the demonstrated ecological toxicity and human health implications of OTCs, investigations and mitigation measures have been formulated worldwide, especially near coastal areas in many developed countries, to assess the effectiveness of the regulations (Dowson et al., 1993a, 1994; Horiguchi et al., 1994; Mora et al., 1995).

Despite efforts made in the past few years, organotin antifouling paints may still be used in many countries with limited regulation enforcement. This results in continuous pollution worldwide. As mentioned above, many industrial products such as fungicides and stabilizers containing OTCs are released when dumped as garbage into the aquatic environment. This poses a serious threat to the coastal marine environment. In China, organotin pollution in coastal zones has been reported sporadically (Xu et al., 1998; Yan et al., 2000; Zhou et al., 2002; Huang et al., 2005; Yang et al., 2006; Zhang et al., 2013). According to the published literature, organotin exists in different environmental media (water, sediment, and biota).

Due to the short half-life of organotin in water, sediment and biota could create the major pools of pollution of metallic Sn and organotin in coastal environments. These substances also have large adsorption and high accumulation in sediment (Stewart and de Mora, 1990; Silva and Rezende, 2002). Zhou et al. (2002) reported that the average levels of monobutyltin (MBT), dibutyltin (DBT), and TBT in sediment were 104, 36, and $354 \mathrm{ng} / \mathrm{g}$, respectively. At the ports of Xiamen, Shantou, and Huiyang, TBT concentrations in sediments were ranging from 0.3 to $174.7 \mathrm{ng} / \mathrm{g}$ (Huang et al., 2005). Moreover, organotin in sediments may release accumulated OTCs to the water column through resuspension, decomposition, or diffusion (Unger et al., 1988; Schnaak et al., 1997). Therefore, monitoring of sediment is essential to analyze the pollution status of organotins and to evaluate their potential environmental risks.

At the same time, monitoring and regulating organotin residues in seafood are regarded as an important route to minimize the potential hazards to human health. In Dalin, China, the average butyltin concentration in marine products was high, up to $3,715 \mathrm{ng} \mathrm{Sn} / \mathrm{g}$ wet weight (Zhou et al., 2002). The past organotin research primarily focused on butyltins (BTs) and overlooked the increasing application of phenyltins (PhTs). Furthermore, there are a limited number of studies considering the degradation of TBT and TPhT and their degradation by-products in sediment and biota. This is important for complete understanding of aquatic fate and transformations of TBT and TPhT.

The Yangtze estuary and adjacent marine environments in the mid-east of China are surrounded by high-density commercial ports, fishing ports, and shipyards. Intensive cargo activities and garbage discharge often deteriorate water quality and increase the chances of organotin contamination and accumulation (Cao et al., 2009). However, the concentrations, speciation, and phase distributions of organotin in sediment remain unclear. The potential risks to the environment, ecosystems, and human health are not yet understood. Moreover, spatial or seasonal changes of organotin are also essential for pinpointing the sources of organotin and developing effective mitigation measures. Thus, the aims of this study are to delineate the distribution, levels, and speciation of organotin in sediments and different biota species in the Yangtze estuary and its adjacent sea. This is not only important for understanding the current organotin pollution characteristics in the Yangtze estuary marine environment but also useful to develop a mitigation framework for source identification and pollution prevention. Finally, potential cancer risks through consuming seafood were analyzed to provide insight into the long-term health risks induced by organotin contamination.

\section{Materials and Methods}

\section{Reagents and standards}

Standard compounds: MBT (97\%), DBT (5\%), TBT (95\%), DPhT (97\%), TPhT (98\%), and tripropyltin (TPrT, 96\%) were obtained from Dr. Ehrenstorfer Co. (Augsburg in Germany). TPrT was used as an internal standard. The stock solutions with a concentration of $1 \mathrm{~g} \mathrm{Sn} / \mathrm{L}$ were prepared by dissolving the accurately weighed MBT, DBT, TBT, DPhT, TPhT, and TPrT into methanol, respectively. All the solutions were stored at $-20^{\circ} \mathrm{C}$ in the dark. Working standard solutions were freshly made before GC analysis. Reference materials, BCR-646 and ERM-CE477, were purchased from European Commission Joint Research Center. Sodium tetraethylborate $\left(\mathrm{NaBEt}_{4}\right.$, $98 \%$ ) was purchased from Dr. Ehrenstorfer Co. (Germany) and freshly made as $1 \%(\mathrm{w} / \mathrm{w})$ solution in ultrapure water before use. Sodium acetate (NaAc) and acetic acid (HAc) were used to prepare the buffer solution $(\mathrm{pH}=4.5)$. All reagents used were analytical reagent grade or better.

\section{Sampling}

A total of 72 surface sediment samples were collected at different locations as shown in Fig. 1a in August 2014. The samples were collected from Chongming Island (1-9), Changxing Island (10-19), Yangshan port (20-28), Luchao port (29-33), and East China Sea (34-72), respectively. Surface sediments $(0-20 \mathrm{~cm})$ were taken $(\sim 500 \mathrm{~g}$ per grab) with a stainless steel pipe dredge $(20 \mathrm{~cm}$ i.d. $\times 20 \mathrm{~cm}$ length $)$ that only allowed us to take from a depth of $20 \mathrm{~cm}$ into the sediment. Surface sediment of $20 \mathrm{~cm}$ is representative of contaminant deposition in recent years, which is comparable with sampling depth of 5-20 cm employed previously (Diez et al., 2002; Jadhav et al., 2009; Flores et al., 2011; Zhang et al., 2013). After shipping the samples back to the laboratory at Tongji University, the sediments were freeze-dried at $-45^{\circ} \mathrm{C}$ for $48 \mathrm{~h}$ and ground until fine particles were obtained.

Biological samples were collected from Luchao port in March, 2015, including these 15 relevant species that live at different depths of water column: Cololnbis snira, Liza carinatus, Fugu ocellatus, Pseudosciaena polyactis, Carassius auratus, Hoplobrotula armata, Tridentiger barbatus, Cynoglessus graclfls, Synechogobius hasta, Odontamblyopus rubicundus, Collichthys lucidus, Portunus sanguinolentus, and Portunus pelagicus (Table 1). Samples were stored in butyltin-free polyethylene bags that were kept in an icecooled box during transportation and then immediately stored at $-20^{\circ} \mathrm{C}$ in the laboratory. Before analysis, the samples were unshelled or unboned, and the edible parts were pooled and thoroughly rinsed with ultrapure water to remove extraneous impurities. After homogenization with a stainless blender, the 

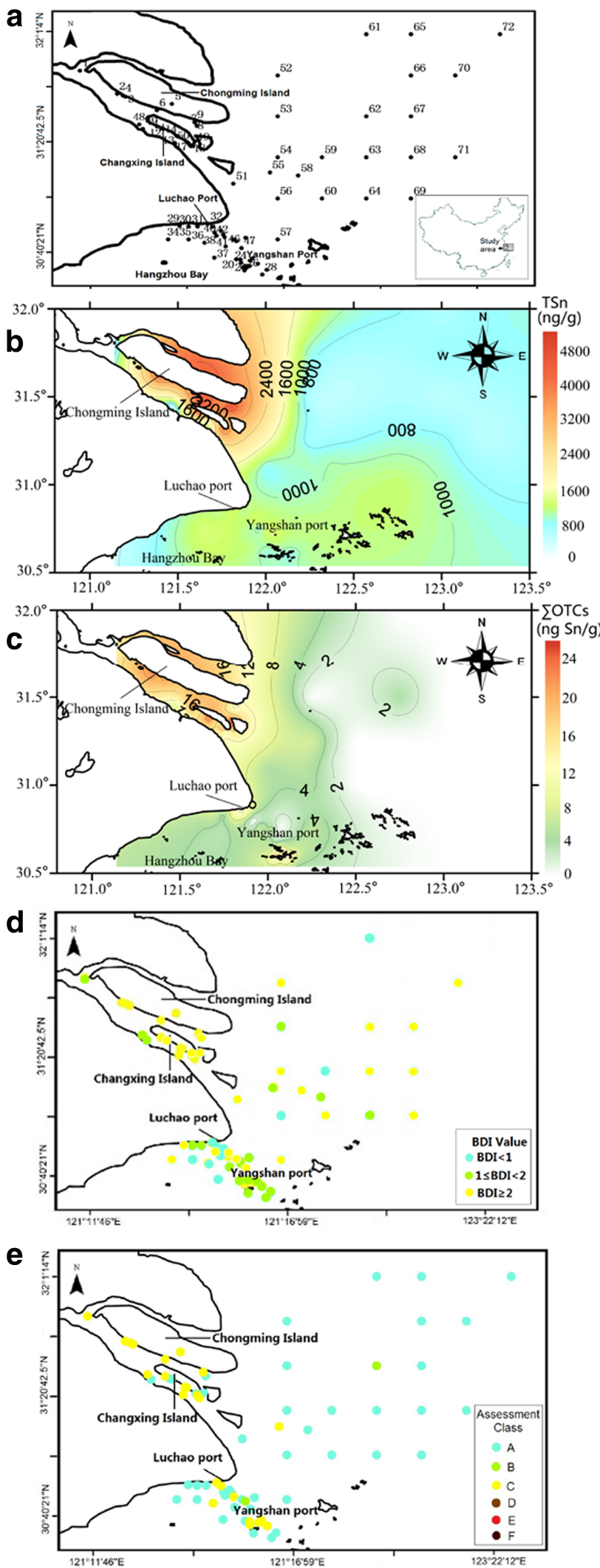

FIG. 1. (a) Study area and sampling sites marked by different numbers. (b) Spatial distribution of total tin in surface sediments of the studied area. (c) Distribution of $\Sigma$ OTCs in the Yangtze estuary and adjacent sea area. (d) BDI value of sediment stations. (e) Assessment class of sediment stations. BDI, butyltin degradation index; OTC, organotin compound. subsamples were freeze-dried and then used for the organotin determination analysis.

\section{Analysis of OTCs}

Sample preparation. Two grams of sediment samples was used for the analysis of organotin. First, the sediment samples were mixed with $100 \mu \mathrm{L}$ of TPrT solution $(1 \mathrm{mg} / \mathrm{L})$ as the internal standard, followed by addition of $10 \mathrm{~mL}$ of $0.03 \%$ tropolone in HAc-methanol $(1: 9, \mathrm{v} / \mathrm{v})$ solution. The samples were vortexed for $1 \mathrm{~min}$ and sonicated for $30 \mathrm{~min}$ in an ultrasonic bath. After stewing for $30 \mathrm{~min}, 5 \mathrm{~mL}$ of supernatant was collected and mixed sequentially with $40 \mathrm{~mL}$ of HAc-NaAc buffer $(1 \mathrm{~mol} / \mathrm{L}, \mathrm{pH} 4.5)$ and $1 \mathrm{~g}$ of $\mathrm{NaCl}$ and $5 \mathrm{~mL}$ of $\mathrm{n}$-hexane in a 70 mL glass vial. Six hundred microliters of $\mathrm{NaBEt}_{4}$ solution $(1 \%$, w/w) was then added into the vial, which was vortexed for $20 \mathrm{~min}$ to derive and extract organotins. The derivative products were cleaned up by injecting the liquid extract through a florisil column $(500 \mathrm{mg} / 6 \mathrm{~mL}, \mathrm{CNW}$ Technologies $\mathrm{GmbH}) . \mathrm{N}$ hexane containing $10 \%$ ethyl ether $(\sim 5 \mathrm{~mL})$ was used to rinse the column to elute the extract. The purification products were concentrated by $\mathrm{N}_{2}$ purging to $\sim 0.5 \mathrm{~mL}$, which was subject to the gas chromatography coupled with mass spectrometer detector (GC-MS) analysis (For each sample injection, $50 \mu \mathrm{L}$ was required).

The analytical procedure of biological samples was similar to that of sediment, except purification. Briefly, $0.5 \mathrm{~g}$ dried biomass per sample was first sonicated with $10 \mathrm{~mL}$ of $0.03 \%$ tropolone in HAc-methanol $(1: 9, \mathrm{v} / \mathrm{v})$ solution for $30 \mathrm{~min}$. Five milliliters of extracts was transferred to a $10-\mathrm{mL}$ glass tube and stored in a refrigerator at $-85^{\circ} \mathrm{C}$ for $2 \mathrm{~h}$. The tube was then centrifuged for $5 \mathrm{~min}$ at $1,000 \mathrm{~g}$. The supernatant was put into another tube with $100 \mathrm{mg}$ primary secondary amine. The tube was vortexed for $10 \mathrm{~min}$ and centrifuged at $1,000 \mathrm{~g}$ for $5 \mathrm{~min}$. The supernatant was retained for organotin derivation. The derivation and purification of organotin from the treated biological samples followed the same procedure as used for sediment samples.

\section{Instrumental analysis}

Concentrations of organotin were determined by a GC-MS system (Shimadzu QP 2010 plus) and the mass spectrometer detector was equipped with electron impact ionization mode $(70 \mathrm{ev})$. An HP-5 capillary column $(30 \mathrm{~m} \times 0.25 \mathrm{~mm} \times$ $0.25 \mu \mathrm{m}$ ) and selected ion monitoring mode were used to separate and detect different possible OTCs. The oven temperature was raised from $60^{\circ} \mathrm{C}$ (held for $1 \mathrm{~min}$ ) to $150^{\circ} \mathrm{C}$ at $10^{\circ} \mathrm{C} / \mathrm{min}$, and then increased at $8^{\circ} \mathrm{C} / \mathrm{min}$ to $290^{\circ} \mathrm{C}$ (held for $2 \mathrm{~min}$ ). The interface temperature of $\mathrm{MS}$ was maintained at $280^{\circ} \mathrm{C}$ and ion source temperature was maintained at $230^{\circ} \mathrm{C}$. High purity of $\mathrm{He}(\geq 99.99 \%)$ was used as carrier gas $(1 \mathrm{~mL} / \mathrm{min})$. Signal collection and data analysis were conducted by the Shimadzu GC solution software.

\section{Quality assurance/quality control}

The entire analytical process of sediment and biological samples was confirmed by determination of reference materials, BCR-646 and EPM-CE477, respectively. The quantitative analysis was performed using the inner standard calibration method. All samples were analyzed in triplicate. Instrument blanks, procedural blanks, and standards were 
Table 1. Biological Data of Aquatic Organisms

\begin{tabular}{lcccc}
\hline Specimen & $\begin{array}{c}\text { Number } \\
\text { of samples }\end{array}$ & $\begin{array}{c}\text { Total } \\
\text { length }(\mathrm{cm})\end{array}$ & $\begin{array}{c}\text { Body } \\
\text { weight }(\mathrm{g})\end{array}$ & $\begin{array}{c}\text { Average moisture } \\
\text { content }(\%)\end{array}$ \\
\hline Fish & & & & \\
$\quad$ Cololnbis snira & 4 & $9.2-12.3$ & $4.95-6.18$ & 76.2 \\
$\quad$ Liza carinatus & 1 & 20.2 & 57.8 & 91.2 \\
$\quad$ Fugu ocellatus & 2 & $8.1-13.4$ & $8.05-33.4$ & 80.1 \\
$\quad$ Pseudosciaena polyactis & 3 & $17.2-18.4$ & $40.2-44.8$ & 82.5 \\
$\quad$ Carassius auratus & 2 & 20.6 & $155-166$ & 81.8 \\
$\quad$ Hoplobrotula armata & 1 & 32.1 & 244 & 78.0 \\
$\quad$ Tridentiger barbatus & 3 & $7.3-10.3$ & $5.51-13.9$ & 74.2 \\
Cynoglessus graclfs & 3 & $12.8-16.4$ & $7.82-11.9$ & 72.2 \\
Synechogobius hasta & 5 & $8.3-11.2$ & $5.12-5.99$ & 79.5 \\
Odontamblyopus rubicundus & 11 & $15.1-23.3$ & $5.49-15.1$ & \\
$\quad$ Collichthys lucidus & 1 & 12.5 & 15.3 & 66.4 \\
Crab & & & & 72.0 \\
$\quad$ Portunus sanguinolentus & 7 & $1.5-2.7$ & $2.13-2.95$ & \\
$\quad$ Portunus pelagicus & 2 & $6.5-9.3$ & $10.3-25.7$ & \\
\hline
\end{tabular}

carried out for every set of 10 environmental samples. Linear regression coefficient displayed a suitable linear correlation $\left(R^{2}>0.995\right)$ within the concentration range of $0-1,000 \mu \mathrm{g} / \mathrm{L}$. The limits of detection for BTs and PhTs were lower than $1 \mathrm{ng} \mathrm{Sn} / \mathrm{g}$.

\section{Analysis of total tin}

Homogenized freeze-dried samples $(0.2 \mathrm{~g})$ were microwave digested in Teflon vessels using a mixture of $\mathrm{HNO}_{3}$, $\mathrm{HCl}$, and $\mathrm{HF}$ according to EPA Method $3052 . \mathrm{HClO}_{4}$ was added to remove $\mathrm{HF}$ and keep a constant volume of $10 \mathrm{~mL}$ with $2 \%(\mathrm{v} / \mathrm{v}) \mathrm{HNO}_{3}$ before using an inductively coupled plasma mass spectrometer (ICP-MS, Agilent7700; USA) to analyze.

\section{Organic carbon and lipid content}

Organic carbon content of the sediment was determined by a TOC analyzer (Shimadzu SSMM-5000A). High purity oxygen was used as the carrier gas $(500 \mathrm{~mL} / \mathrm{min})$. The temperatures for determining inorganic carbon (IC) and total carbon (TC) were $900^{\circ} \mathrm{C}$ and $200^{\circ} \mathrm{C}$, respectively. Glucose and anhydrous sodium sulfate $\left(\mathrm{Na}_{2} \mathrm{SO}_{4}\right)$ were used as standard reference materials for determination of TC and IC, respectively. The content of TOC was obtained by subtracting the content of IC from that of TC.

Five grams of dried aquatic organisms was used to analyze the content of lipid. Biota samples were extracted twice with $40 \mathrm{~mL}$ of FOLCH solution (chloroform: methanol=2:1). After centrifuging $(1,000 \mathrm{~g}, 5 \mathrm{~min})$, the supernatants were mixed and $60 \mathrm{~mL}$ of ultrapure water was added. After stewing for $30 \mathrm{~min}$, the chloroform layer was separated and then dried with anhydrous $\mathrm{Na}_{2} \mathrm{SO}_{4}$. The lipid content was obtained and measured by weight after solvent evaporation.

\section{Results and discussion}

\section{Concentrations of total tin and organotins in sediment}

The total concentration of $\mathrm{Sn}$ in surface sediments of the Yangtze estuary and adjacent sea area was $472.6-5,158 \mathrm{ng} / \mathrm{g}$ with an average of $1,670 \mathrm{ng} / \mathrm{g}$. Figure $1 \mathrm{~b}$ shows the spatial distribution of total tin concentrations in the sediments. Clearly, the Yangtze estuary is characterized with high levels of Sn pollution compared with adjacent sea areas. The concentrations of subspecies of organotin (MBT, DBT, TBT, $\mathrm{DPhT}$, and TPhT) in sediments from the Yangtze estuary and adjacent sea area were up to $18.1,8.86,6.45,3.91$, and $3.66 \mathrm{ng} \mathrm{Sn} / \mathrm{g} \mathrm{dw}$ (dry weight), respectively. The sum of those five OTC concentrations ( $\Sigma$ OTCs) was up to $26.4 \mathrm{ng} \mathrm{Sn} / \mathrm{g}$, which accounted for $\sim 2.10 \%$ of the total tin. Thus, $\Sigma$ OTCs only contributed to a small portion of the total tin. Most of the tin existed in the inorganic form. According to the classification scheme of Dowson et al. (1993b), 65.3\% of sediment samples were classified as unpolluted (TBT $\leq 1.2 \mathrm{ng} \mathrm{Sn} / \mathrm{g}$ ) and $34.7 \%$ were light polluted by TBT $(1.2-8.2 \mathrm{ng} \mathrm{Sn} / \mathrm{g})$. TBT pollution mainly occurred on Chongming Island, Changxing Island, Yangshan port, and Luchao port, which accounted for $88.9 \%, 88.9 \%, 44.4 \%$, and $40.0 \%$ among all the sampling stations in these regions, respectively. Several studies have detected BTs in sediments of ports and estuaries in other parts of China (Table 2). The concentrations of phenyltins were not included due to the lack of published data. Compared with those values reported elsewhere (Lei, 2003; Huang et al., 2005; Dong et al., 2015), the concentrations of BTs in Luchao port and Yangshan port were similar to those in Yantai port and Kaohsiung port, but less than those reported in Tianjin port, Xiamen port, Shantou port, Shanwei port, and Huiyang port. The levels of BTs obtained from the Yangtze estuary in this study were similar to those in Jen-Gen estuary, Minjiang estuary, Jiulongjiang estuary, and Zhujiang estuary, but significantly lower than those in Haihe estuary. Generally speaking, the concentrations of BTs in sediments from the Yangtze estuary and its adjacent sea area were relatively low, especially after the implementation of regulatory measures in 2008. However, the concentrations of BTs are likely influenced by many factors, such as the development of industry and agriculture, shipping activity, hydraulic events, seasonal variations, and pollution sources of different geographical locations. Therefore, it is necessary to monitor the long-term changes of organotin pollution in sediment after enforced regulation. 
a

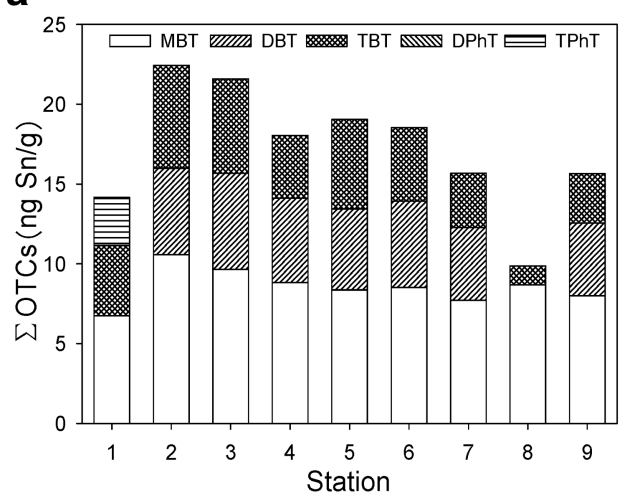

C

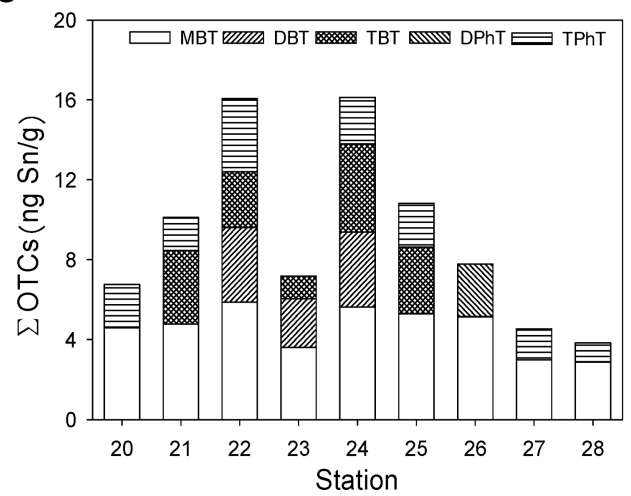

Spatial distribution and pollution sources of organotins in sediment

According to the inverse distance weighted method (IDW), spatial distribution of $\Sigma$ OTCs in sediments from the Yangtze estuary and adjacent sea area was simulated and is

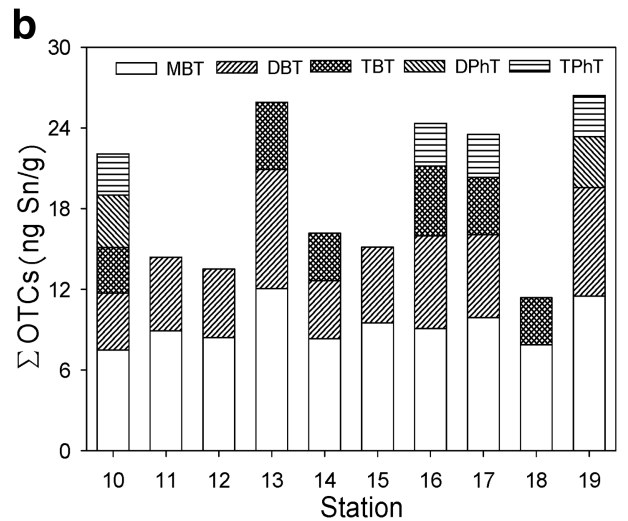

d

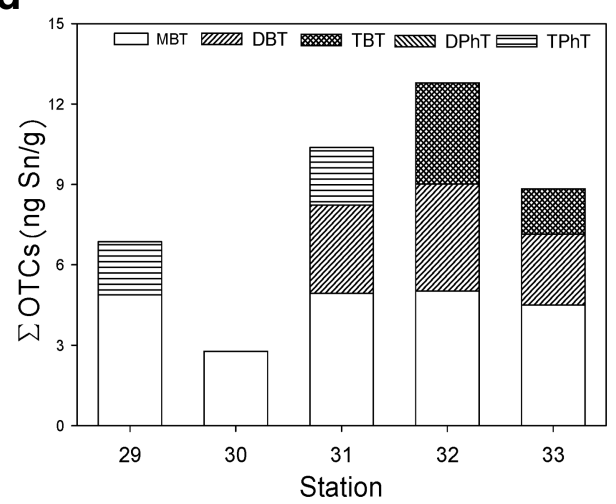

FIG. 2. Distribution of $\Sigma$ OTCs in Chongming Island (a), Changxing Island (b), Yangshan port (c), and Luchao port (d).

Table 2. Distribution of Butyltins in Sediments in Various Locations in China (NG/G DW)

\begin{tabular}{|c|c|c|c|c|c|c|}
\hline Location & & $\begin{array}{c}\text { Sampling } \\
\text { year }\end{array}$ & $M B T$ & $D B T$ & $T B T$ & Reference \\
\hline Port & $\begin{array}{c}\text { Throughput } \\
\text { capacity } \\
\text { (×10,000 ton) }\end{array}$ & & & & & \\
\hline Xiamen Port & $17,227.3$ & 2001 & $4.8-39.2$ & nd & $6.9-174.7$ & Huang et al. (2005) \\
\hline Shantou Port & $4,562.79$ & 2001-2002 & $4.8-76.6$ & $\mathrm{nd}-0.5$ & $0.8-14.7$ & Huang et al. (2005) \\
\hline Shanwei Port & 771.69 & 2002 & $6.39-393.9$ & nd & $0.92-6.08$ & Lei (2003) \\
\hline Huiyang Port & 9,574 & 2002 & $34-103.2$ & nd-0.4 & $2.8-10.2$ & Huang et al. (2005) \\
\hline Haimen Port & $\approx 200$ & 2002 & $2.52-78.87$ & nd -0.45 & $2.14-18.69$ & Lei (2003) \\
\hline Tianjin Port & 47,697 & 2008 & 17.03 & 43.89 & 125.36 & Wu et al. (2009) \\
\hline Yantai Port & 27,030 & 2008 & nd & nd & 4.92 & Wu et al. (2009) \\
\hline Kaohsiung Port & $5,000-6,000$ & 2009 & $0.7-5.4$ & $0.5-26.1$ & $2.3-27.6$ & Dong et al. (2015) \\
\hline Luchao Port & $\approx 1,000$ & 2014 & $4.10-7.44$ & nd-7.82 & nd-9.22 & This work \\
\hline Yangshan Port & 11,800 & 2014 & $4.28-8.69$ & nd-7.37 & nd- -10.8 & This work \\
\hline \multicolumn{7}{|l|}{ Estuary } \\
\hline Haihe estuary & & 1992-1995 & nd -18.2 & $29.6-814$ & $50.8-1860$ & Xu et al. (1998) \\
\hline Zhujiang estuary & & 1996 & $0.09 *$ & $0.04 *$ & nd & Yuan et al. (2001) \\
\hline Minjiang estuary & & 1996 & nd-12.62 & nd -1.53 & nd-0.91 & Yuan et al. (2001) \\
\hline Jiulongjiang estuary & & 1996-1999 & $0.07 *-1.76$ & nd-6.99 & nd-24.03 & Yuan et al. (2001) \\
\hline Jen-Gen estuary & & 2009 & $0.5-6.8$ & $0.6-7.0$ & $4.1-31.1$ & Dong et al. (2015) \\
\hline Yangtze estuary & & 2014 & $9.97-17.0$ & nd-17.4 & nd-15.7 & This work \\
\hline
\end{tabular}

The throughput capacities of ports were from the statistical data in 2012.

DBT, dibutyltin; MBT, monobutyltin; nd, not detectable; TBT, diphenyltin.

*Indicates below detection limit.

shown in Fig. 1c. Higher $\Sigma$ OTCs levels were found in similar patterns as the total tin levels and were particularly high in samples from Chongming Island, Changxing Island, Yangshan port, and Luchao port, indicative of the intensive input of organotins in these areas. $\Sigma$ OTC concentrations in sediments decreased with increasing distance away from the 
coastlines, highlighting the impact of human activities on organotin pollution formation.

Figure $2 \mathrm{a}, \mathrm{b}$ compares $\Sigma$ OTC concentrations in sediment in stations 1-9 from Chongming Island and stations 10-19 from Changxing Island, respectively. Among 19 stations, the highest

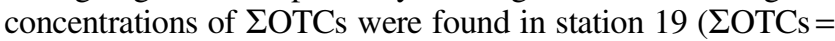
$26.4 \mathrm{ng} \mathrm{Sn} / \mathrm{g}$ ) located at the fishing port, followed by station 13 and station 16 located near the fishing port and shipyard. There were a large number of fishing ports in Chongming Island and Changxing Island. Thus, TBT could be leached from the boats docked at the pier. Additionally, there were some shipyards located on the banks of the two islands, where antifouling paints potentially contain and release organotin pollution to the Yangtze estuary. For example, concentrations of TBT in sediments from stations 2 and 3 near the shipyard were higher than those from other sampling stations, while TBT was not detected in stations 11, 12, and 15 far from fishing port and shipyard, indicating that antifouling paint on ships probably contributes to organotin pollution in surface sediments of the Yangtze estuary.

Figure 2c, d shows the distribution of $\Sigma$ OTC concentrations in sediment samples of Yangshan port and Luchao port. The $\Sigma$ OTC concentrations in the two commercial ports were relatively lower than those in the two islands, following the rank of Changxing Island $(19.3 \pm 5.70 \mathrm{ng} \mathrm{Sn} / \mathrm{g})>$ Chongming Island $(17.2 \pm 3.88 \mathrm{ng} \mathrm{Sn} / \mathrm{g})>$ Yangshan port $(9.26 \pm 4.49 \mathrm{ng}$ $\mathrm{Sn} / \mathrm{g})>$ Luchao port $(8.33 \pm 3.79 \mathrm{ng} \mathrm{Sn} / \mathrm{g})$. Yangshan port and Luchao port are both important commercial ports, rendering higher shipping activities than the ports of Chongming Island and Changxing Island. However, the $\Sigma$ OTC concentrations of sediments near the two islands are relatively greater than those near the two ports. This could be due to hydrodynamic mixing in Yangshan port and Luchao port enhanced by the dispersion or convective transport of organotins. Moreover, there may be other sources of organotins near the two islands.

\section{BT pollution characteristics}

Of the three BTs, the structure of TBT is not stable and easy to decompose by UV irradiation, biological, and chemical reactions. The degradation produces two primary products: DBT and MBT. As the intermediate product, DBT is unstable, while the end product, MBT, can last longer in the environment (Seligman et al., 1986; Huang et al., 1998). By tracking the ratios of DBT and MBT over TBT or so-called butyltin degradation index (BDI), we can predict the phases of TBT contamination and the source (Burton et al., 2005):

$$
\mathrm{BDI}=\frac{[\mathrm{MBT}]+[\mathrm{DBT}]}{[\mathrm{TBT}]}
$$

The map of BDI distribution is shown in Fig. 1d. Twelve percent of the 72 sediment samples exhibited BDI values $<1$, indicative of the presence of fresh input of TBT and low degradation of BTs in the Yangtze estuary; $27.5 \%$ of the sediment samples showed $1 \leq \mathrm{BDI}<2$, implying moderate degradation of TBT to DBT and MBT, while $59.5 \%$ showed BDI value $\geq 2$, indicating rapid degradation rate and existence of input sources for MBT and DBT at these locations. In general, the observed BDI $<2$ was mainly found in Yangshan and Luchao ports, where BTs may come from TBT that has relatively slow degradation. As a major component of antifouling paints, the organotin pollution in these two ports likely originated from antifouling paints
(Cao et al., 2009). By contrast, the sediments near Chongming Island and Changxing Island were with BDI value $\geq 2$, indicating that the degradation rate of TBT was fast and MBT and DBT may come from both the degradation processes of TBT and other land-based sources (Dubalska et al., 2013), such as industry wastewater and city sewage, as mentioned above.

\section{PhT pollution characteristics}

As another important model compound of organotins, PhTs were detected near the northern bank of Hangzhou bay, where fungicide is heavily applied in the aquacultural and agricultural bases. DPhT is a degradation product of TPhT and can be further degraded to MPhT. In this study, the high levels of PhTs were not well associated with that of TBT, although TPhT is used as fungicide and antifouling paints together with TBT (Stab et al., 1996). Among the studied sediments, PhTs could only be detected in 28 sediment samples. In all detectable stations, most of the ratios of TPhT/DPhT were higher than 1, suggesting a possible fresh flux of TPhT entering Yangtze estuary.

\section{Level and distribution of organotin in biota samples}

Concentrations of different organotin species in the biota samples were determined and are shown in Fig. 3. The detection rate of organotins in aquatic organisms collected from Luchao port was $92.3 \%$, indicating that almost all the marine organism products except $C$. auratus had organotin accumulation. The BT concentration was found to be up to $49.2 \mathrm{ng} \mathrm{Sn} / \mathrm{g}$ dw for MBT, $42.0 \mathrm{ng} \mathrm{Sn} / \mathrm{g} \mathrm{dw}$ for DBT, and $241.6 \mathrm{ng} \mathrm{Sn} / \mathrm{g} \mathrm{dw}$ for TBT, respectively. Shim et al. (2005) reported that comparable TBT concentrations in bivalves and fish from the coast of Korea were in the range of 16-1,610 and 7-323 $\mathrm{ng} \mathrm{Sn} / \mathrm{g} \mathrm{dw}$, respectively. Sudaryanto et al. (2004) reported that TBT in muscle of fish from the coast of Malaysia was in the range of $2.4-190 \mathrm{ng} / \mathrm{g}$ ww (wet weight). Barroso et al. (2004) reported that TBT in the range of 11-789 $\mathrm{ng} \mathrm{Sn} / \mathrm{g} \mathrm{dw}$ was determined in mussel from west coast of Portugal. Our observed TBT concentrations in marine products in Luchao port were lower than the above reported levels.

$\mathrm{DPhT}$ and TPhT in our aquatic organisms reached the maximum levels of 29.6 and $29.8 \mathrm{ng} \mathrm{Sn} / \mathrm{g} \mathrm{dw}$, respectively. Apparently, PhTs had lower concentrations than BTs. TPhT concentrations in marine products of Luchao port were also lower than the previously reported values for samples in ports from Japan and Taiwan. For example, Harino et al. (2000) reported that TPhT in the muscle of fish from Osaka Port in Japan ranged from 11 to $182 \mathrm{ng} / \mathrm{g}$ ww. Lee et al. (2009) reported that TPhT in clams from Hualien county in Taiwan ranged from $<5.7$ to $68.7 \mathrm{ng} / \mathrm{g}$ ww.

Figure 3a shows that concentrations of OTCs varied in different species, probably due to organotin exposure conditions, their different dietary patterns, physiology, and uptake of OTCs (Gao et al., 2006). Among the 13 kinds of marine products, the highest concentration $(301.5 \mathrm{ng} \mathrm{Sn} / \mathrm{g}$ $\mathrm{dw}$ ) of total organotins was found in C. lucidus, while organotins were not detectable in $C$. auratus.

Concentrations of organotins in marine products are closely related to the surrounding environment. The average concentration of aquatic organisms living in upper water column was $22.3 \mathrm{ng} \mathrm{Sn} / \mathrm{g} \mathrm{dw}$, including $C$. snira and L. carinatus. Aquatic organisms living in the middle and lower water column had an average concentration of $36.7 \mathrm{ng} \mathrm{Sn} / \mathrm{g}$ dw, including $F$. ocellatus, $P$. polyatis, C. auratus, H. armata, 

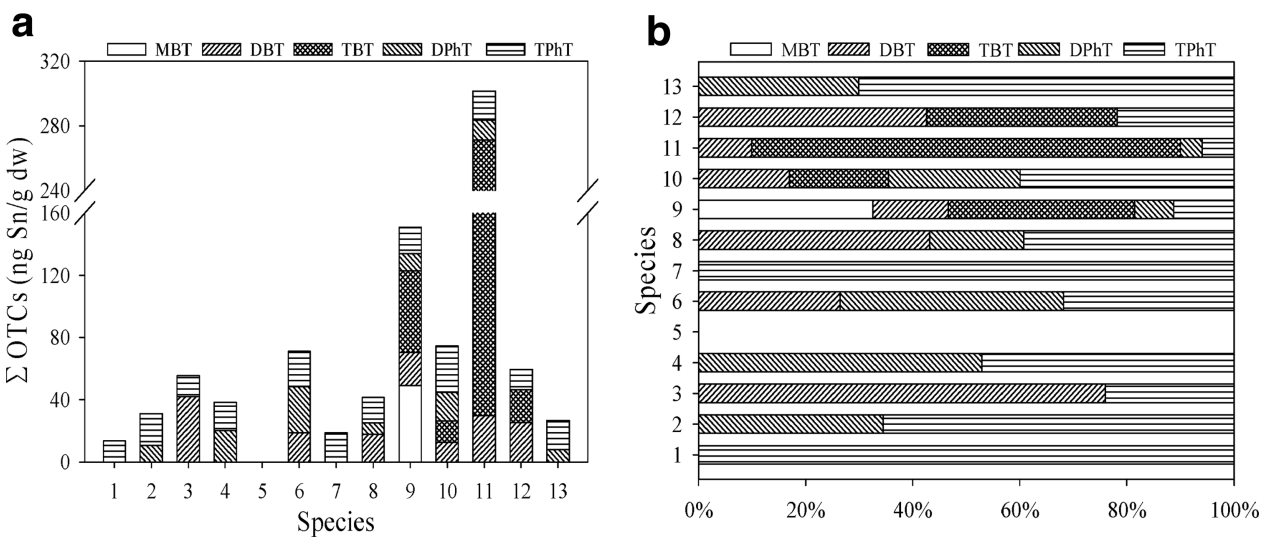

FIG. 3. (a) Distribution and composition of total organotin patterns in biological samples collected from Luchao port. Aquatic organism species in (b) represent 1-Cololnbis snira; 2-Liza carinatus; 3-Fugu ocellatus; 4-Pseudosciaena polyactis; 5Carassius auratus; 6-Hoplobrotula armata; 7-Tridentiger barbatus; 8-Cynoglessus graclfls; 9-Symechogobius hasta; 10Odontamblyopus rubicundus; 11-Collichthys lucidus; 12-Portunus sanguinolentus; and 13-Portunus pelagicus.

and $T$. barbatus. In muddy sediment, the average organotin concentration of aquatic organisms was much higher (109 ng $\mathrm{Sn} / \mathrm{g} \mathrm{dw}$ ), which agrees with previous findings reported by Jadhav et al. (2011). Organotins in water would be prone to photodegradation and their half-lives were generally short, but the half-lives of organotins can be months or even years in sediment. Thus, the concentration of organotins would be higher in benthic species than in pelagic species. Among the five species living in the middle and lower water column, concentrations of organotins in the other four marine products were similar (Fig. 3), except for C. auratus, which feeds on plants, while others feed on fish, shrimp, or shell. Clearly, different dietary patterns or burrowing habit can result in varying amounts of accumulated concentrations of organotins in marine products. The concentration of $\Sigma$ OTCs in $P$. sanguinolentus was $59.4 \mathrm{ng} \mathrm{Sn} / \mathrm{g} \mathrm{dw}$, while in $P$. pelagicus, it was $26.6 \mathrm{ng} \mathrm{Sn/g} \mathrm{dw.} \mathrm{Guérin} \mathrm{et} \mathrm{al.} \mathrm{(2007)} \mathrm{indicated} \mathrm{that}$ different bioaccumulation abilities of crab were mainly due to the intraspecific variance and seasonal variances instead of the organotin concentration in the environment. Crab has weaker bioaccumulation ability than other marine organisms in the same area (Santos et al., 2009; Jadhav et al., 2011).

\section{Accumulation and degradation of organotins by biota samples}

The route of organotin exposure to biota leads to different bioaccumulation depending on different degradation or digestion by liver or kidney. To compare the bioaccumulation and availability of different species of organotin, biota sediment accumulation factor (BSAF) was calculated as follows (Moore et al., 2005):

$$
\mathrm{BSAF}=\frac{[\mathrm{OTC}]_{\mathrm{b}}}{[\text { lipid content }]_{\mathrm{b}}} \times \frac{[\mathrm{OTC}]_{\mathrm{s}}}{[\text { organotin carbon }]_{\mathrm{s}}} .
$$

BSAF characterizes the bioaccumulation tendency of organic contaminants in lipid tissues relative to organic carbon in sediment. The calculated BSAFs in Table 3 show that both biota samples containing TBT had BSAFs of higher than 1 and had a high bioaccumulation potential. The highest accumulation factor of TBT was found in C. lucidus. However, BSAF of DBT in this organism was less than 1 , suggesting that bioac- cumulation of TBT in $C$. lucidus was high with slow degradation. By contrast, in F. ocellatus, BSAF for TBT was 0 (no bioaccumulation probably due to biological degradation). BSAF for TPhT ranged from 0 to 5.30 for different samples. The average BSAF of TPhT was higher than that of TBT, which indicated that TBT may be more easily metabolized by organisms than TPhT. Most of the aquatic organisms had BSAFs of TPhT higher than 1, suggesting that they had high tendency of bioaccumulation for TPhT from sediments. The concentration of DPhT in sediment was below the detection limit, but in most aquatic organisms, DPhT was detected, which suggests that some organotin species (DPhT or TPhT) may have further biomagnification, while other organotin species could be digested by aquatic organisms.

\section{Potential environmental risks}

Potential environmental risks of sediments were evaluated using TBT toxicity guidelines. Two TBT screening values proposed by US USEPA (1996) and the ACCI (Assessment Class Criterion for Imposex) proposed by OSPAR (2009) were used. According to USEPA, LSV (lower screening value) and HSV (higher screening value) were 5.15 and $72.04 \mathrm{ng} \mathrm{Sn/g}$

TABLE 3. BSAFs OF ORganotins IN Biota SAMPLES FROM LUCHAO PORT

\begin{tabular}{llllcl}
\hline & \multicolumn{5}{c}{ BSAFs } \\
\cline { 2 - 6 } Specimen & MBT & $D B T$ & $T B T$ & DPhT & $T P h T$ \\
\hline C. snira & 0 & 0 & 0 & 0 & 0.46 \\
L. carinatus & 0 & 0 & 0 & $>0.30$ & 1.60 \\
F. ocellatus & 0 & 2.91 & 0 & 0 & 1.98 \\
$P$. polyactis & 0 & 0 & 0 & $>0.40$ & 0.98 \\
C. auratus & 0 & 0 & 0 & - & 0 \\
H. armata & 0 & 1.17 & 0 & $>1.44$ & 3.04 \\
T. barbatus & 0 & 0 & 0 & 0 & 1.54 \\
C. graclfls & 0 & 0.46 & 0 & $>0.15$ & 0.90 \\
S. hasta & 0.76 & 0.75 & 3.38 & $>0.30$ & 1.30 \\
O. rubicundus & 0 & 1.05 & 2.07 & $>1.17$ & 5.30 \\
C. lucidus & 0 & 0.38 & 5.62 & $>0.12$ & 0.50 \\
P. sanguinolentus & 0 & 0.66 & 1.00 & - & 0.73 \\
\hline
\end{tabular}

BSAF, Biota sediment accumulation factor; DPhT, diphenyltin; TPhT, triphenyltin. 
$1 \%$ TOC (with $1 \%$ TOC calibration), respectively. In this research, with the mass content of TBT in the sediments with $1 \%$ TOC calibration, the range of TBT was 0 to $8.8 \mathrm{ng} \mathrm{Sn} / \mathrm{g}$ 1\%TOC. Among 72 sediment stations, 11 stations had TBT levels in the sediment between the LSV-HSV values, thus presenting lower ecological toxicity. It is again worth mentioning that these stations were mainly located near fishing ports and commercial ports or shipyards. The rest of the stations had TBT levels in the sediment below the LSV and thus presented none or negligible ecological toxicity. Based on ACCI, there are six classes of TBT concentrations: not detected (Class A); $<2 \mathrm{ng}$ TBT/g dw (Class B); 2-50 ng TBT/g dw (Class C); 50-200 ng TBT/g dw (Class D); 200-500 ng TBT/g dw (Class E); and $>500 \mathrm{ng}$ TBT/g dw (Class F). The classification of sediment stations is shown in Fig. 1e, where $30.6 \%$ of stations should be classified as Class $\mathrm{C} ; 8.3 \%$ as Class B; and all other stations as Class A. The Class $\mathrm{C}$ stations are located near Chongming Island, Changxing Island, Yangshan port, and Luchao port.

Marine products are one of the primary sources of protein for human society and thus the consumption of OTCcontaminated seafood may pose adverse impacts on human health. Although the toxicology of organotins in human beings has not been fully understood, tolerable average residue levels (TARLs) for TBT (or TPhT) can be estimated to assess the potential human health risk (Belfroid et al., 2000):

$$
\text { TARL }=\frac{(\text { TDI } \times 60 \mathrm{~kg} \mathrm{bw})}{\text { average daily seafood consumption }}
$$

where TDI is the total daily intake (estimated values could be adopted from previous studies: $0.25 \mu \mathrm{g}$ TBT $/ \mathrm{kg} / \mathrm{bw} / \mathrm{day}$ [Penninks, 1993] and $0.5 \mu \mathrm{g} \mathrm{TPhT} / \mathrm{kg} / \mathrm{bw} / \mathrm{day}$ [World Health Organization, 1992]) and bw is the body weight (60 kg is used here) (Kannan and Falandysz, 1997). According to the average seafood consumption of a Chinese person ( $68.8 \mathrm{~g} /$ day, FAO, 1997-1999), TARL for seafood in China is estimated to be $218 \mathrm{ng} \mathrm{TBT} / \mathrm{g}$ and $436 \mathrm{ng}$ TPhT/g. Clearly, the concentrations of TBT and TPhT in all the aquatic organisms were lower than the recommended TARL values by about two orders of magnitude, thereby presenting a low human health risk.

\section{Conclusion}

To delineate the potential organotin pollution in Yangtze estuary and its adjacent marine environment, this work presented a systematic investigation of the total tin $(1,670 \mathrm{ng} / \mathrm{g}$ in average) and five different major organotin species in sediments and aquatic organisms collected from 13 different locations. In general, the concentrations of OTCs in sediments only contribute to a small fraction $(2.10 \%)$ of the total tin. The geographical distributions of total tin and total OTCs were similar and showed a decline away from the Yangtze estuary due to the significant impacts of human activities (e.g., antifouling paints on boats and pesticides) on organotin pollution. OTCs were detected in all aquatic organisms with different levels in Luchao port except $C$. auratus, indicating that bioaccumulation of organotin in aquatic organisms depends on factors such as exposure conditions, dietary patterns, and uptake or digestion. Under our assumed food digestion conditions, the human health risk from exposure to organotin was estimated to be low. The new findings lay the groundwork toward a deeper understanding of current organotin pollution characteristics in Yangtze estuary marine environment and may have certain implications on other estuary and harbor regions in the world where cargo and industrial activities may cause potential organotin pollution. Such investigations are critical for identifying the sources and establishing a mitigation framework of pollution prevention.

\section{Acknowledgments}

The authors would like to express their utmost gratitude to the National Natural Science Foundation of China (No. 41101499), State Key Laboratory of Pollution Control and Resource Reuse Foundation (No. RCRRE 16011), the National Key Technologies R\&D program of the Ministry of Science and Technology of China (2012BAJ24B01), and the Swedish Research Council (contract Dnr. 639-2013-6913).

\section{Author Disclosure Statement}

No competing financial interests exist.

\section{References}

Alzieu, C. (1998). Tributyltin: Case study of a chronic contaminant in the coastal environment. Ocen. Coast. Manage. 40, 23. Antizar-Ladislao, B. (2008). Environmental levels, toxicity and human exposure to tributyltin (TBT)-contaminated marine environment. A review. Environ. Int. 34, 292.

Barroso, C.M., Mendo, S., and Moreira, M.H. (2004). Organotin contamination in the mussel Mytilus galloprovincialis from portuguese coastal waters. Mar. Pollut. Bull. 48, 1149.

Belfroid, A.C., Purperhart, M., and Ariese, F. (2000). Organotin levels in seafood. Mar. Pollut. Bull. 40, 226.

Burton, D.E., Phillips, I.R., and Hawker, D.W. (2005). In-situ partitioning of butyltin species in estuarine sediments. Chemosphere. $59,585$.

Cao, D.D., Jiang, G.B., Zhou, Q.F., and Yang, R.Q. (2009). Organotin pollution in China: An overview of the current state and potential health risk. J. Environ. Manage. 90, S16.

Deng, L., Liu, G.H., Zhang, H.M., and Xu, H.L. (2015). Levels and assessment of organotin contamination at Futian Mangrove Wetland in Shenzhen, China. Reg. Stud. Mar. Sci. 1, 18.

Diez, S., Abalos, M., and Bayona, J. (2002). Organotin contamination in sediments from the Western Mediterranean enclosures following 10 years of TBT regulation. Water Res. 36, 905.

Dong, C.D., Chen, C.F., and Chen, C.W. (2015). Composition and source of butyltins in sediments of Kaohsiung Harbor, Taiwan. Estuar. Coast Shelf S. 156, 134.

Dowson, P.H., Bubb, J.M., and Lester, J.N. (1993a). Temporal distribution of organotins in the aquatic environment: Five years after the 1987 UK retail ban on TBT based antifouling paints. Mar. Pollut. Bull. 26, 482.

Dowson, P.H., Bubb, J.M., and Lester, J.N. (1994). The effectiveness of the 1987 retail ban on TBT based antifouling paints in reducing butyltin concentrations in East Anglia, UK. Chemosphere. 28, 905.

Dowson, P.H., Bubb, J.M., Williams, T.P., and Lester, J.N. (1993b). Degradation of tributyltin in freshwater and estuarine marina sediments. Water Sci. Technol. 28, 133.

Dubalska, K., Rutkowska, M.G., Bajger-Nowak, G., Konieczka, P., and Nik, J.N. (2013). Organotin compounds: Environmental fate and analytics. Crit. Rev. Anal. Chem. 43, 35.

Flores, M., Bravo, M., Pinochet, H., Maxwell, P., and Mester, Z. (2011). Tartaric acid extraction of organotin compounds from sediment samples. Microchem. J. 98, 129.

Gao, J.M., Hu, J.Y., and Zheng, Z.G. (2006). Organotin residues in marine organisms. Mar. Sci. 30, 65. 
Guérin, T., Sirot, V., Volatier, J.L., Leblanc, J.C., and Al, E. (2007). Organotin levels in seafood and its implications for health risk in high-seafood consumers. Sci. Total Environ. 388, 66.

Harino, H., Fukushima, M., and Kawai, S. (2000). Accumulation of butyltin and phenyltin compounds in various fish species. Arch. Environ. Con. Tox. 39, 13.

Heidrich, D.D., Steckelbroeck, S., and Klingmuller, D. (2001). Inhibition of human cytochrome $\mathrm{P} 450$ aromatase activity by butyltins. Steroids. 66, 763.

Hoch, M. (2001). Organotin compounds in the environmentAn overview. Appl. Geochem. 16, 719.

Horiguchi, T., Shiraishi, H., and Morita, M.S.M. (1994). Imposex and organotin compounds in Thais clavigera and $T$. bronni in Japan. J. Mar. Biol. Assoc. UK. 74, 651.

Huang, C.J., Dong, Q.X., Lie, Z., Wang, Z.X., and Zhou, K. (2005). An investigation of organotin compound contamination in three harbors along southeast coast of China. Acta Oceanol. Sin. 27, 57.

Huang, G.L., Chen, Z.Q., and Dai, S.G. (1998). Adsorption behavior of butyltin compounds of suspended particulate matter in water body. Acta Sci. Circum. 18, 27.

Jadhav, S., Bhosale, D., and Bhosle, N. (2011). Baseline of organotin pollution in fishes, clams, shrimps, squids and crabs collected from the west coast of India. Mar. Pollut. Bull. 62, 2213.

Jadhav, S., Bhosle, N.B., Massanisso, P., and Morabito, R. (2009). Organotins in the sediments of the Zuari estuary, west coast of India. J. Environ. Manage. 90, S4.

Kannan, K., and Falandysz, J. (1997). Butyltin residues in sediment, fish, fish-eating birds, harbour porpoise and human tissues from the Polish coast of the Baltic Sea. Mar. Pollut. Bull. 34, 203.

Lee, C-C., Jhuang, Y-F., Liu, L-L., Hsieh, C-Y., Chen, C.S., and Tien, C-J. (2009). The major source and impact of phenyltin contamination on freshwater aquaculture clam Corbicula fluminea and wild golden apple snail Pomacea canaliculata. Environ. Chem. 6, 341.

Lei, Z. (2003). Studys on the Determination of Organotins and Surveys on Organotins Pollution in Harbors Along the Southeast Coast of China. Guangzhou: Jinan University.

Ling, S.X., and Sun, H.W. (2004). Progress in studies of environmental organotin pollution and monitoring method. $J$. Environ. Health. 21, 425.

Moore, D.W., Baudo, R., Conder, J.M., Landrum, P.F., McFarland, V.A., Meador, J.P., and Word, J.Q. (2005). Bioaccumulation in the Assessment of Sediment Quality: Uncertainty and Potential Application. In RJ Wenning, GE Batley, CG Ingersoll, and DW Moore, Eds. Use of Sediment Quality Guidelines and Related Tools for the Assessment of Contaminated Sediments. Pensacola, FL: SETAC Press, pp. 429-496.

Mora, S.J.D., Stewart, C., and Phillips, D. (1995). Sources and rate of degradation of tri(n-butyl)tin in marine sediments near Auckland, New Zealand. Mar. Poll. Bull. 30, 50.

OSPAR. (2009).Co-ordinated Environment Monitoring Programme (CEMP) Assessment Report. 2008/2009 Assesment of trends and concentrations of selected hazardous substance in sediments and biota. London.

Penninks, A.H. (1993). The evaluation of data-derived safety factors for bis(tri-n-butyltin)oxide. Food Addit. Contam. 10, 351.

Santos, M.M., Enes, P., Reis-Henriques, M.A., Kuballa, J., Castro, L.F.C., and Vieira, M.N. (2009). Organotin levels in seafood from Portuguese markets and the risk for consumers. Chemosphere. 75, 661.

Schnaak, W., Küchler, T., Kujawa, M., Henschel, K.P., Sü Enbach, D., and Donau, R. (1997). Organic contaminants in sewage sludge and their ecotoxicological significance in the agricultural utilization of sewage sludge. Chemosphere. 35, 5. Seligman, P.F., Valkirs, A.O., and Lee, R.F. (1986). Degradation of tributyltin in San Diego Bay, California, waters. Environ. Sci. Techno. 20, 1229.

Shim, W.J., Yim, U.H., Kim, N.S., Sang, H.H., Oh, J.R., Jeon, J.K., and Okamura, H. (2005). Accumulation of butyl- and phenyltin compounds in starfish and bivalves from the coastal environment of Korea. Environ. Pollut. 133, 489.

Silva, M.A.L., and Rezende, C.E. (2002). Behavior of selected micro and trace elements and organic matter in sediments of a freshwater system in south-east Brazil. Sci. Total Environ. 292, 121.

Stab, J.A., Traas, T.P., Stroomberg, G., van Kesteren, J., Leonards, P., van Hattum, B., and Brinkman, U.A. (1996). Determination of organotin compounds in the foodweb of a shallow freshwater lake in The Netherlands. Arch. Environ. Con. Tox. 31, 319.

Stewart, C., and de Mora, S.J. (1990). A review of the degradation of tri(n-butyl)tin in the marine environment. Environ. Technol. 11, 565 .

Sudaryanto, A., Takahashi, S., Iwata, H., Tanabe, S., and Ismail, A. (2004). Contamination of butyltin compounds in Malaysian marine environments. Environ. Pollut. 130, 347.

Unger, M.A., MacIntyre, W.G., and Huggett, R.J. (1988). Sorption behavior of tributyltin on estuarine and freshwater sediments. Environ. Tox. Chem. 7, 907.

USEPA. (1996). Recommendation for Screening Value for Tributyltin in Sediments at Superfund Sites in Puget Sound, Washington. DCN 4000-09-013-AADK, and 33-01-AAAV. Prepared by Roy F. Weston. Inc., Seattle, Washington. Prepared for US Environmental Protection Agency Superfund Program Region X, Settle. Washington.

Whalen, M., and Loganathan, B.K. (1999). Immunotoxicity of environmentally relevant concentrations of butyltins on human natural killer cells in vitro. Environ. Res. 81, 108.

Whalen, M.M., and Loganathan, B.G. (2001). Butyltin exposure causes a rapid decrease in cyclic AMP levels in human lymphocytes. Toxicol. Appl. Pharm. 171, 141.

World Health Organization (WHO). Pesticide Residues in Food-1991 evaluations. Part II-Toxicology. WHO/PCS/92.52, Geneva, 1992.

Wu, W.Q., Zhang, B., Yao, Z.W., and Feng, X. (2009). Monitoring and analyzing on organotin compound in main ports of Bohai Bay of China. J. Dalian Maritime Univ. 35, 115.

Xu, X.B., Dai, S.G., and Huang, Y.-Y. (1998). Changes of Typical Chemical Pollutants in the Environment and Their Ecological Effects. Beijing: Science Press.

Yan, J., Zhang, G., Min, Y.S., Sheng, G.Y., and Fu, J.M. (2000). Primary determination of butyltins in sediments of Pearl River Delta. Res. Environ. Sci. 13, 43.

Yang, R.Q., Zhou, Q.F., Liu, J.Y., and Jiang, G.B. (2006). Butyltins compounds in molluscs from Chinese Bohai coastal waters. Food Chem. 97, 637.

Yuan, D.X., Zhong, S.M., and Yang, D.N. (2001). Distribution of organotins in surface sediment of Western Xiamen Harbour and Minjiang Estuary. J. Oceanogr. Taiwan. 20, 91.

Zhang, K.G., Shi, J.B., He, B., Xu, W.H., Li, X.D., and Jiang, G.B. (2013). Organotin compounds in surface sediments from selected fishing ports along the Chinese coast. Chin. Sci. Bull. 58, 231.

Zhou, Q.F., Jiang, G.B., and Liu, J.Y. (2002). Organotin pollution in China. Sci. World J. 2, 655.

Zhu, S.S., Hu, F.T., Ning, G.A.N., Cao, Y.T., and Pan, D.D. (2012). Progress in research on pretreatment method for organotin in environment. J. Ningbo Univ. Technol. 24, 65. 